\title{
Training Chemists for Administration
}

$\mathrm{I}^{\mathrm{N}}$ a series of articles published in recent issues of the Industrial Chemist, there will be found many pertinent observations and useful suggestions regarding the problems connected with the training of chemists for administrative posts in industry. In an editorial, it is pointed out that chemists have all too often been regarded as unfitted for high administrative positions, a disability which they have been alleged to share with other scientific workers. Few technical men are to be found on boards of directors and in managerial positions. Incidentally, this peculiarity is one of the many distinctions between British and German technical industry.

In the August number, Mr. R. Brightman, in an article on "Some Problems of Industrial Recruitment and Leadership", remarks that industry does not appear to have considered seriously as yet whether training for management might not well be given at an intermediate stage in an industrial career, when those undergoing the training have some store of industrial experience on which to draw. If such training were limited to those who have afforded indications both of the capacity and the ambition for high administrative posts, such as is required from naval and military officers before undergoing advanced theoretical training in naval war schools or staff colleges, industry may possibly find in it one solution of the problem of securing a supply of administrators of the requisite quality.

Mr. Brightman argues that much closer co-operation is required between industry and education as well as more intimate knowledge of each other's requirements. Our existing educational facilities when fully utilised should be adequate for industrial requirements subject to (I) the reorganisation of elementary education on the lines recommended by the Hadow Committee, and (2) the gradual transfer of technical education from evening classes to part-time day instruction.
In the September issue of the Industrial Chemist, Mr. H. Lewis writes on training for administration in the chemical industry. Previously, he points out, it was possible to obtain most of the knowledge required by working through the departments of a firm, and this is the method adopted by small firms at the present, and often by the large firms through a trainee system. There are, however, many serious obstacles in the way of obtaining an adequate understanding of the varied problems of management of a large organisation by this method, and at best, it often becomes merely an instructional course in the methods of production. It is rarely that breadth of outlook can be obtained from experience in an individual firm, and resort must therefore be made to some other method of obtaining this necessary adjunct for effective management. Facilities for the study of administrative subjects are now becoming increasingly available in various centres, but so far it would appear that the only systematically organised institutional course in England dealing specifically with administration in chemical works is that provided by the Manchester College of Technology in the Department of Industrial Administration ; the subjects comprised in this course being economics, organisation of industry and commerce, industrial history, chemical economics and markets and chemical works organisation.

In the October number, Mr. H. Housley suggests that the chemical industry can usefully employ several groups of chemists; there will be a large group who have decided to make chemical work their vocation, but others might combine the training and experience of the chemist with that of accountancy or engineering or administration. He argues that industry requires a number of schools situated in the more important industrial centres, each offering an organised course in administration covering a period of two or possibly three sessions.

\section{Studies in Perseveration}

$\Delta \mathrm{T}$ an inter-sectional discussion on perseveration $A$ in Section $J$ (Psychology) of the British Association meeting at Aberdeen, Dr. Wynn Jones, who opened the discussion, indicated that manifestations of perseveration may be classified in various ways, for example, as affective, conative, ideational, sensory or motor aspects of mentality. The study of the interrelation between these forms of persevera. tion has not received adequate attention. He further pointed out that investigators agree in finding evidence for a common factor in the motor tests. It was also suggested on the basis of a preliminary investigation with siblings as subjects that it may be possible to determine whether any of the alleged manifestations of perseveration are subject to hereditary influences.

Dr. W. Stephenson discussed the terms clearness variation, secondary function, perseverative tendency, general inertia, perseverations and stereotypies. In a series of propositions it was suggested that (1) there is a $p$-factor, but its explanation might lie in clearness variation and its laws; (2) the $p$-factor makes contact with estimates of character, but the explanation of the contact is open to doubt--it cannot be accepted, for example, that general inertia is a fundamental principle subserving the formation of character and conduct generally; (3) suggestions for the required fundamental principle would seem to come from (a) the observed facts of compulsion-repetitions, (b) the underlying principle being either that described by Freud as "beyond the pleasure-pain principle" (the "death instinct"), (c) or a psychical process impelling activities towards reinstatement of an earlier condition, now, however, a purely unconscious process.

Dr. P. E. Vernon criticised perseveration tests on the grounds that they have in the past been chiefly of a sensory or motor type. Temperament and character may be regarded as organised hierarchically, and in order to measure the 'higher levels' (that is, the more fundamental and significant traits), it is essential to use higher level approaches, that is, test situations which seem meaningful and important to the subject who is tested. Most sensori-motor tests tend to appear trivial or artificial to the subject, and in spite of their objectivity and statistical 